\title{
Brain, mind and behaviour - emerging biological connections Amresh Shrivastava
}

\author{
Address: University of western Ontario, London, Regional Mental Health care, Ontario, Canada \\ from International Society on Brain and Behaviour: 3rd International Congress on Brain and Behaviour \\ Thessaloniki, Greece. 28 November - 2 December 2007 \\ Published: 17 April 2008 \\ Annals of General Psychiatry 2008, 7(Suppl I):S82 doi:I0.II86/I744-859X-7-SI-S82
}

This abstract is available from: http://www.annals-general-psychiatry.com/content/7/SI/S82

(C) 2008 Shrivastava; licensee BioMed Central Ltd.

Connections of brain, mind and behavior have always been interesting exploration for scholars of the subject. We have lived through the era of 'Brainless Mind' and 'Mindless Brain' in explanation of normal and abnormal human behavior argued by every one from psychoanalysts to neurochemists.

The last twenty years have seen tremendous advancement in the field of neuroscience. Few important developments have been crucial to such developments e.g. 1.declaration of 'Decade of Brain' 1990 to year 2000 brought new focus, funding and collaborations in investigation of brain. 2.advancement in biomedical sciences and imaging for development of sophisticated tools, probes and machines to allow direct data accessibility such as in MRI or fMRI. 3.devlopment of reliable system of clinical diagnosis and phenomenology, which brought uniformly in the language of psychiatry through classification systems, 4.informations from human Genome project, 5. Practice of evidence bases medicine, all these initiative have unfolded what was just a matter of speculation few decades back. The success was remarkable and year 2000 Noble prize was given to a team of three distinguished neuroscientists who attempted unfolding the 'biochemical process of memory'. Cognition and memory provides the opportunity of interface of biology, psychology and behavioral medicine. Development of the field of Cognitive neuron science has been a grate achievement, which explains not only how information is repressed or stored through conditioning but also that the process can be experimentally supported by animal experiments. These emerging connections of brain to environment have a series of changes and each set of change is dedicated in a discipline of neuroscience. Now we have many models of normal behaviors, personality traits and pathological behaviour.the series involves a genetic component, a neuronal cell, few neurotransmitter substances, and neuro- anatonical locations, defining the development of pathology in a longitudinal model. More and more research in providing more valid and evidence based information for newer frontiers of human life e.g. antenatal and neonatal learning, Cognitive enhancement, spectrum of mood, biology of consciousness and the 'unconsciousness'.

The brain, mind and behavior, which appeared so disconnected few decades back are now units of continuous process for information processing and retrieval. Advancements in Conditioning and organization theories, neuronal plasticity, and phenotypes of genetic propensities are few aspects, which will explain complex human emotion and pathology to bring relief to millions who are suffering from pathology of brain mind and behavior. 